\title{
Beryllium Metaphosphate
}

National Cancer Institute

\section{Source}

National Cancer Institute. Beryllium Metaphosphate. NCI Thesaurus. Code C45880.

A white colored, crystalline, inorganic compound that emits toxic fumes of beryllium oxides and phosphorus oxides upon heating. Beryllium metaphosphate is used in small amounts for special ceramic compositions and as a catalyst in organic reactions. Inhalation exposure to its dust irritates the nose, throat and lungs and can cause pneumonitis. Prolonged exposure can result in a chronic beryllium disease called berylliosis causing granuloma and fibrosis formation in the lungs. Beryllium is associated with an increased risk of developing lung cancer. ( $\mathrm{NCl05)}$ 